\title{
Genetic polymorphisms in TNIP1 increase the risk of gastric carcinoma
}

\author{
Zhao Liu ${ }^{1,2}$, Yuting Shi ${ }^{3}$, Yuyan Na ${ }^{4}$, Qi Zhang ${ }^{5}$, Sizhe Cao ${ }^{5}$, Xianglong Duan ${ }^{6}$, Xiyang \\ Zhang', Hua Yang', Tianbo Jin', Yiming Li ${ }^{1}$ \\ ${ }^{1}$ Department of General Surgery, The Second Affiliated Hospital, Xi'an Jiaotong University, Xi'an 710004, China \\ ${ }^{2}$ Department of Surgery, Xi'an Chest Hospital, Xi'an TB\&Thoracic Tumor Hospital, Xi'an 710100, China \\ ${ }^{3}$ Department of Medical Oncology, Graduate School of Inner Mongolia Medical University, Hohhot 010000, China \\ ${ }^{4}$ Department of Pediatric Orthopedics, The Second Affiliated Hospital of Inner Mongolia Medical University, Hohhot 010030, \\ China \\ ${ }^{5}$ Department of Medical, Xi'an Chest Hospital, Xi'an TB\&Thoracic Tumor Hospital, Xi'an 710100, China \\ ${ }^{6}$ Second Department of General Surgery, Shaanxi Province People's Hospital, Xi'an 710001, China \\ ${ }^{7}$ Department of Biochemistry, School of Life Sciences, Northwest University, Xi'an 710069, China \\ Correspondence to: Yiming Li, email: 15024979153@163.com
}

Keywords: gastric carcinoma, single nucleotide polymorphisms (SNPS), TNF- $\alpha$-induced protein 3-interacting protein 1 (TNIP 1), casecontrol study

Received: March 30, $2016 \quad$ Accepted: May 13, $2016 \quad$ Published: May 26, 2016

\section{ABSTRACT}

The distribution and levels of TNIP1 in malignant and normal gastric mucosa are different, but it is not known whether TNIP1 polymorphisms are related to gastric carcinogenesis. To assess the association between four TNIP1 SNPs (rs3792792, rs4958881, rs7708392, rs10036748) and carcinogenesis, we used Sequenom MassARRAY technology to determine the genotypes of $\mathbf{3 0 2}$ gastric carcinoma patients and $\mathbf{3 0 0}$ healthy controls in a Northwest Chinese Han population. These data were then compared using the Chi-square test/Fisher's exact test, genetic model analysis, and haplotype analysis. Odds ratios (OR) and $95 \%$ confidence intervals (CI) were used to evaluate the correlation. We observed that patients with the "G" allele of rs7708392 and the " $C$ " allele of rs10036748 showed an increased risk of gastric carcinoma (OR= 1.335, 95\%CI: 1.021-1.745, $P=0.035$; OR=1.358, 95\%CI: $1.039-$ 1.774, $P=0.025$, respectively). Conversely, the haplotype "CT" of TNIP1 (rs7708392rs10036748) may act as a genetic protective factor for gastric carcinoma (adjusted $\mathrm{OR}=0.731,95 \% \mathrm{CI}: 0.552-0.970, P=0.030$ ). Our results are the first to suggest that genetic variation in TNIP1 gene is associated with gastric carcinoma, though, this finding must be confirmed in other populations with larger sample size.

\section{INTRODUCTION}

About one million new cases of gastric carcinoma (GC) were estimated to have occurred in 2008, making it the fourth most common malignant tumor worldwide. GC was the second leading cause of cancer-related death 738,000 deaths in the world. The incidence of GC was highest in Eastern Asia and the highest mortality rate was observed in Eastern Asia, specifically in China [1]. Since symptoms of early stage GC are not typical, patients usually diagnosed in the advanced stage after the optimal time for therapy. Although surgery, chemotherapy, and radiotherapy have improved the survival of early stage patients [2], the therapy and prognosis of advanced patients are still poor [3]. Given the lethality of GC on survival, identification of risk factors for oncogenesis and new strategies for primary prevention are necessary.

The pathogenesis of GC is not completely clear. $\mathrm{GC}$ is a complex and heterogeneous disease influenced by genetic and environmental factors [4]. Environmental factors including dietary habits, smoking and chronic atrophic gastritis caused mainly by Helicobacter pylori infections are known GC risk factors [5]. However, not all people exposed to these hazards eventually suffer from 
Table 1: Characteristics of cases and controls in this study

\begin{tabular}{lccc}
\hline Variable & $\begin{array}{c}\text { Cases } \\
(\mathbf{n = 3 0 2})\end{array}$ & $\begin{array}{c}\text { Controls } \\
(\mathbf{n = 3 0 0 )}\end{array}$ & $\begin{array}{c}\boldsymbol{P} \text { value } \\
\text { Sex }\end{array}$ \\
Male & $233(77.2 \%)$ & $180(60.0 \%)$ & $<0.001$ \\
Female & $69(22.8 \%)$ & $120(40.0 \%)$ & $<0.001$ \\
Age, yr & 58.01 & 60.42 & \\
\hline
\end{tabular}

$P$ values were calculated from pearson Chi-square test.

GC; for example, only 3\% people infected with $\mathrm{H}$. pylori develop GC $[6,7]$. Hence, genetic susceptibility may play a more important role in gastric carcinogenesis.

TNF- $\alpha$-induced protein 3 -interacting protein 1 (TNIP1) on chromosome 5q33, also known as VAN, NAF1, ABIN-1, and nip40-1, encodes an A20-binding protein which plays an important role in autoimmunity, chronic inflammation, and cancer through the inhibition of nuclear factor kappa-B (NF$\kappa \mathrm{B})$ activation [8]. Epidermal growth factor receptor (EGFR) induced activation of the transcription factor $\mathrm{NF}-\kappa \mathrm{B}$ may be involved in the malignant behavior of EGFR overexpressing tumor cells, such as in lung cancer and gastric carcinoma [9, 10]. L Huang et al. believed that EGF-induced NF- $\kappa \mathrm{B}$ activation could be inhibited by overexpression of ABINs, including ABIN1. Knockdown of ABIN-1 by RNA interference boosted the NF- $\kappa$ B response to EGF stimulation [11]. We propose that TNIP1 might be a protective gene involved in the inhibition of oncogenesis.

In several malignant tissues, TNIP1 staining is often altered from its distribution and levels in normal tissues, such as in gastric lining, glandular epithelia with moderate cytoplasmic and weak nuclear staining, while far less staining tended to be associated with cell periphery. Igor Gurevich et al. thought the altered distribution and levels of TNIP1 in malignant tissues may affect processes in which TNIP1 is involved, such as NF- $\kappa \mathrm{B}$ signaling, possibly contributing to malignant tumor development [8]. We set out to determine whether TNIP1 is related to gastric carcinogenesis.

The TNIPl gene has been implicated in susceptibility to a number of autoimmune diseases, such as systemic lupus erythematosus (SLE), systemic sclerosis and rheumatoid arthritis (RA). Single nucleotide polymorphisms in the $H L A-D R B 1$ [12-14] and IL23R genes [15, 16] can alter susceptibility to GC and autoimmune diseases, such as SLE and systemic sclerosis. But, whether TNIP1 gene is also the shared risk gene for GC and autoimmune diseases is unknown.

To investigate the association between TNIP1 and GC risk, we genotyped 4 variants associated with SLE and systemic sclerosis [17-19], rs3792792, rs4958881, rs7708392, rs10036748, and analyzed the difference between GC patients and matched controls from the Chinese Han population from Northwest China.

\section{RESULTS}

302 GC patients and 300 healthy controls were enrolled in our study. We show that age $(P<0.001)$ and gender $(P<0.001)$ were significantly different between GC cases and health controls in Table 1 . In order to eliminate those residual confounding effects, the variable of age and gender were adjusted in multivariate unconditional logistic regression analysis.

The candidate TNIP1 gene SNPs (rs3792792, rs4958881, rs7708392, and rs10036748) were genotyped in GC patients and healthy controls. One SNP (rs4958881) was excluded due to significant deviation from HardyWeinberg equilibrium $(P<0.05)$; the remaining three SNPs were in accordance with the Hardy-Weinberg equilibrium in the control group with a value of $P>0.05$. We compared the differences in frequency distributions of alleles between GC cases and controls by Chi-square test/ Fisher's exact test and found two significant SNPs in the TNIP1 gene were associated with GC risk (Table 2). The frequency of the " $G$ " allele of rs7708392 and the " $C$ " allele of rs 10036748 were significantly higher in GC cases than in controls $(26.0 \%$ versus $20.8 \% ; 26.3 \%$ versus $20.8 \%$, respectively). And the " $G$ " allele of rs7708392 and the " $C$ " allele of rs 10036748 showed significantly increased risk of $\mathrm{GC}(\mathrm{OR}=1.335,95 \% \mathrm{CI}: 1.021-1.745, P=0.035$; $\mathrm{OR}=$ $1.358,95 \% \mathrm{CI}: 1.039-1.774, P=0.025$, respectively). The frequencies of heterozygous variants "GC" genotype in rs7708392 and "CT" genotype in rs10036748 significantly differed in GC cases and controls (Table 3). After further adjustment by age and gender, the difference of "GC" genotype in rs7708392 and "CT" genotype in rs10036748 remains significant (adjusted $\mathrm{OR}=1.433,95 \% \mathrm{CI}$ : 1.013 $2.029, P=0.042$; adjusted $\mathrm{OR}=1.446,95 \% \mathrm{CI}: 1.021-$ $2.048, P=0.038$, respectively)

Next, we assumed that the minor allele of each SNP was a risk factor and analyzed the association between each variant and GC under three genetic models (Table 4). Two susceptibility SNPs were found to be associated with increased risk of GC both before and after the adjustment: rs7708392 under the dominant model (adjusted OR= 
Table 2: Allele frequencies in cases and controls and odds ratio estimates for gastric carcinoma

\begin{tabular}{|c|c|c|c|c|c|c|c|c|}
\hline \multirow{2}{*}{ SNP } & \multirow{2}{*}{ Chromosome } & \multirow{2}{*}{ Position } & \multirow{2}{*}{ Allele } & \multicolumn{2}{|c|}{ Minor allele frequency } & \multirow{2}{*}{$\begin{array}{c}\text { HWE } P \\
\text { value }\end{array}$} & \multirow{2}{*}{ OR $(95 \% C I)$} & \multirow{2}{*}{$P^{a}$} \\
\hline & & & & Case & Control & & & \\
\hline rs3792792 & 5 & 150440506 & $\mathrm{C} / \mathrm{T}$ & 0.076 & 0.062 & 1.0000 & $1.254(0.801-1.964)$ & 0.321 \\
\hline rs4958881 & 5 & 150450236 & $\mathrm{C} / \mathrm{T}$ & 0.119 & 0.114 & $3.30 \mathrm{E}-45$ & $1.056(0.739-1.511)$ & 0.763 \\
\hline rs7708392 & 5 & 150457485 & $\mathrm{G} / \mathrm{C}$ & 0.260 & 0.208 & 0.8612 & $1.335(1.021-1.745)$ & $0.035^{*}$ \\
\hline rs 10036748 & 5 & 150458146 & $\mathrm{C} / \mathrm{T}$ & 0.263 & 0.208 & 0.8612 & $1.358(1.039-1.774)$ & $0.025^{*}$ \\
\hline
\end{tabular}

HWE: Hardy-Weinberg equilibrium; OR: odds ratio; 95\%CI: 95\% confidence interval.

${ }^{a} P$ values were calculated from Chi-square test/Fisher's exact test.

$* P \leq 0.05$ indicates statistical significance.

Table 3: Genotypes of the four SNPs and their associations with risk of gastric carcinoma

\begin{tabular}{|c|c|c|c|c|c|c|c|}
\hline \multirow{2}{*}{ SNP } & \multirow{2}{*}{ Genotype } & \multicolumn{2}{|c|}{ Genotype frequency } & \multicolumn{2}{|c|}{ Without adjustment } & \multicolumn{2}{|c|}{ With adjustment } \\
\hline & & $\operatorname{Cases}(\mathbf{N})$ & Controls(N) & OR $(95 \% C I)$ & $P^{a}$ & OR $(95 \% C I)$ & $P^{b}$ \\
\hline \multirow[t]{3}{*}{ rs3792792 } & TT & 261 & 264 & 1.000 & - & 1.000 & - \\
\hline & $\mathrm{CT}$ & 36 & 35 & $1.040(0.634-1.708)$ & 0.876 & $1.116(0.668-1.865)$ & 0.674 \\
\hline & $\mathrm{CC}$ & 5 & 1 & $5.057(0.587-43.580)$ & 0.140 & $5.766(0.621-53.580)$ & 0.123 \\
\hline \multirow[t]{3}{*}{ rs4958881 } & TT & 258 & 257 & - & - & - & - \\
\hline & $\mathrm{CT}$ & 0 & 0 & - & - & - & - \\
\hline & $\mathrm{CC}$ & 35 & 33 & - & - & - & - \\
\hline \multirow[t]{3}{*}{ rs7708392 } & $\mathrm{CC}$ & 162 & 187 & 1.000 & - & 1.000 & - \\
\hline & GC & 123 & 101 & $1.406(1.004-1.969)$ & $0.048^{*}$ & $1.433(1.013-2.029)$ & $0.042 *$ \\
\hline & GG & 17 & 12 & $1.635(0.758-3.526)$ & 0.210 & $1.518(0.689-3.344)$ & 0.300 \\
\hline \multirow[t]{3}{*}{ rs 10036748} & TT & 161 & 187 & 1.000 & - & 1.000 & - \\
\hline & $\mathrm{CT}$ & 123 & 101 & $1.414(1.010-1.982)$ & $0.044 *$ & $1.446(1.021-2.048)$ & $0.038^{*}$ \\
\hline & $\mathrm{CC}$ & 18 & 12 & $1.742(0.815-3.726)$ & 0.152 & $1.606(0.736-3.506)$ & 0.235 \\
\hline
\end{tabular}

SNP: Single nucleotide polymorphism; OR: odds ratio; 95\%CI: 95\% confidence interval.

${ }^{\text {a }} P$ values were calculated from unconditional logistic regression analysis.

${ }^{\mathrm{b}} P$ values were calculated by unconditional logistic regression analysis with adjustments for age and gender.

$* P \leq 0.05$ indicates statistical significance.

1.443, 95\%CI: $1.032-2.017, P=0.032)$ and under the additive model (adjusted $\mathrm{OR}=1.346,95 \% \mathrm{CI}$ : $1.013-1.786$, $P=0.040)$ and rs10036748 under the dominant model (adjusted $\mathrm{OR}=1.464,95 \% \mathrm{CI}: 1.047-2.047, P=0.026)$ and under the additive model (adjusted $\mathrm{OR}=1.367,95 \% \mathrm{CI}$ : 1.031-1.813, $P=0.030)$.

Finally, the haplotypes with frequencies of more than 0.05 were selected for further research (Table 5). In Figure 1, the red squares of the TNIP1 linkage disequilibrium (LD) block exhibited statistically significant linkage between rs7708392 and rs10036748. We observed that the "CT" haplotype was more frequent among GC cases and may have a protective effect against
GC both before and after the adjustment (adjusted OR= 0.731, 95\%CI: 0.552-0.970, $P=0.030$ ).

\section{DISCUSSION}

The present case-control study of 302 GC patients and 300 healthy controls was designed to investigate whether the four variants within the TNIP1 gene are related to the risk of developing GC. We found that rs7708392 and rs10036748 in the TNIP1 gene were significantly associated with GC risk in the Chinese Han population of Northwest China. The "G" allele of rs7708392 and the "C" allele of rs 10036748 were identified as risk alleles for 
Table 4: Association between SNPs and gastric carcinoma in multiple inheritance models

\begin{tabular}{|c|c|c|c|c|c|c|}
\hline \multirow{2}{*}{ SNP } & \multirow{2}{*}{ Model } & \multirow{2}{*}{ Genotype } & \multicolumn{2}{|c|}{ Without adjustment } & \multicolumn{2}{|c|}{ With adjustment } \\
\hline & & & OR $(95 \% \mathrm{CI})$ & $P^{a}$ & OR $(95 \% C I)$ & $P^{b}$ \\
\hline \multirow[t]{5}{*}{ rs3792792 } & Dominant & $\mathrm{T} / \mathrm{T}$ & 1 & & 1 & \\
\hline & & $\mathrm{C} / \mathrm{C}+\mathrm{C} / \mathrm{T}$ & $1.152(0.713-1.860)$ & 0.563 & $1.236(0.752-2.032)$ & 0.404 \\
\hline & Recessive & $\mathrm{C} / \mathrm{T}+\mathrm{T} / \mathrm{T}$ & 1 & & 1 & \\
\hline & & $\mathrm{C} / \mathrm{C}$ & $5.034(0.585-43.340)$ & 0.141 & $5.687(0.613-52.760)$ & 0.126 \\
\hline & Additive & - & $1.234(0.801-1.900)$ & 0.341 & $1.315(0.837-2.064)$ & 0.235 \\
\hline \multirow[t]{5}{*}{ rs4958881 } & Dominant & $\mathrm{T} / \mathrm{T}$ & 1 & & 1 & \\
\hline & & $\mathrm{C} / \mathrm{C}+\mathrm{C} / \mathrm{T}$ & $1.056(0.637-1.752)$ & 0.831 & $1.129(0.668-1.908)$ & 0.652 \\
\hline & Recessive & $\mathrm{C} / \mathrm{T}+\mathrm{T} / \mathrm{T}$ & 1 & & 1 & \\
\hline & & $\mathrm{C} / \mathrm{C}$ & $1.056(0.637-1.752)$ & 0.831 & $1.129(0.668-1.908)$ & 0.652 \\
\hline & Additive & - & $1.028(0.798-1.324)$ & 0.831 & $1.062(0.817-1.381)$ & 0.652 \\
\hline \multirow[t]{5}{*}{ rs7708392 } & Dominant & $\mathrm{C} / \mathrm{C}$ & 1 & & 1 & \\
\hline & & $\mathrm{G} / \mathrm{G}+\mathrm{G} / \mathrm{C}$ & $1.430(1.033-1.980)$ & $0.031 *$ & $1.443(1.032-2.017)$ & $0.032 *$ \\
\hline & Recessive & $\mathrm{G} / \mathrm{C}+\mathrm{C} / \mathrm{C}$ & 1 & & 1 & \\
\hline & & $\mathrm{G} / \mathrm{G}$ & $1.432(0.672-3.052)$ & 0.353 & $1.319(0.606-2.871)$ & 0.485 \\
\hline & Additive & - & $1.351(1.027-1.778)$ & $0.032 *$ & $1.346(1.013-1.786)$ & $0.040^{*}$ \\
\hline \multirow[t]{5}{*}{ rs 10036748} & Dominant & $\mathrm{T} / \mathrm{T}$ & 1 & & 1 & \\
\hline & & $\mathrm{C} / \mathrm{C}+\mathrm{C} / \mathrm{T}$ & $1.449(1.047-2.006)$ & $0.025 *$ & $1.464(1.047-2.047)$ & $0.026^{*}$ \\
\hline & Recessive & $\mathrm{C} / \mathrm{T}+\mathrm{T} / \mathrm{T}$ & 1 & & 1 & \\
\hline & & $\mathrm{C} / \mathrm{C}$ & $1.521(0.720-3.216)$ & 0.272 & $1.390(0.645-2.998)$ & 0.401 \\
\hline & Additive & - & $1.373(1.045-1.806)$ & $0.023 *$ & $1.367(1.031-1.813)$ & $0.030 *$ \\
\hline
\end{tabular}

SNP: Single nucleotide polymorphism; OR: odds ratio; 95\%CI: 95\% confidence interval.

${ }^{a} P$ values were calculated from unconditional logistic regression analysis.

${ }^{\mathrm{b}} P$ values were calculated by unconditional logistic regression analysis with adjustments for age and gender.

$* P \leq 0.05$ indicates statistical significance.

Table 5: TNIP1 haplotype frequencies and the association with gastric carcinoma risk

\begin{tabular}{|c|c|c|c|c|c|c|}
\hline \multirow[t]{2}{*}{ Haplotype block } & \multicolumn{2}{|c|}{$\begin{array}{l}\text { Haplotype } \\
\text { frequencies }\end{array}$} & \multicolumn{2}{|c|}{ Without adjustment } & \multicolumn{2}{|c|}{ With adjustment } \\
\hline & Case & Control & OR $(95 \% C I)$ & $P^{a}$ & OR $(95 \% C I)$ & $P^{b}$ \\
\hline $\mathrm{CT}$ & 0.737 & 0.792 & $0.728(0.554-0.957)$ & $0.023 *$ & $0.731(0.552-0.970)$ & $0.030^{*}$ \\
\hline GCA & 0.331 & 0.328 & $1.014(0.791-1.299)$ & 0.915 & $1.011(0.783-1.307)$ & 0.931 \\
\hline
\end{tabular}

OR: odds ratio; 95\% CI: 95\% confidence interval.

${ }^{a} P$ values were calculated from unconditional logistic regression analysis.

${ }^{\mathrm{b}} P$ values were calculated by unconditional logistic regression analysis with adjustments for age and gender.

$* P \leq 0.05$ indicates statistical significance. 
the development of GC. We also found that a haplotype "CT" of TNIP1 gene was associated with a $27 \%$ reduction in the risk of GC.

However, it was surprising that TNIP1 heterozygotes (GC for rs7708392 and CT for rs10036748) rather than homozygotes were significantly associated with GC risk. The phenomenon may be explained by the co-dominant heredity in which each of the two different alleles has its own effects on the specific protein synthesis and function. This assumption should be tested in future gene functional experiments.

$\mathrm{NF}-\kappa \mathrm{B}$ is constitutively activated in GC and activated or deregulated NF- $\mathrm{kB}$ is related to several aspects of oncogenesis, including promoting tumor cell proliferation, preventing apoptosis, and increasing tumor angiogenesis potentials $[20,21]$. Nevertheless NF- $\kappa B$ activity is tightly controlled by several regulatory proteins, such as TNIP1 (ABIN-1) which can inhibit the NF- $\mathrm{kB}$ activation induced by tumor necrosis factor, interleukin-1, EGF and lipopolysaccharide [11, 22]. We regarded
TNIP1 as a "protective" gene that may be involved in the inhibition of GC development. It is possible that polymorphisms that down-regulate expression of TNIP1 gene render individuals susceptible to GC. This speculation is supported by our results that the " $G$ " allele of rs7708392 and the "C" allele of rs 10036748 were potential risk factors for gastric carcinogenesis.

Aya Kawasaki et al. found that rs 7708392 was an risk factor for SLE in a Japanese population. Other studies observed that SNPs rs7708392 and rs10036748 in TNIP1 are in strong linkage disequilibrium with SLE. As Sahil Gambhir and colleagues described, inflammation and gastrointestinal cancers can be connected by a critical mechanism of the NF-kB pathway [23]. Chronic infections and autoimmune processes give rise to prolonged specific inflammation which induces constitutive NF- $\mathrm{\kappa B}$ activity, increasing the probability of developing specific cancers through downstream proteins. As a result, we conclude that polymorphisms in the TNIP1 gene increase the possibility of developing neoplasms.

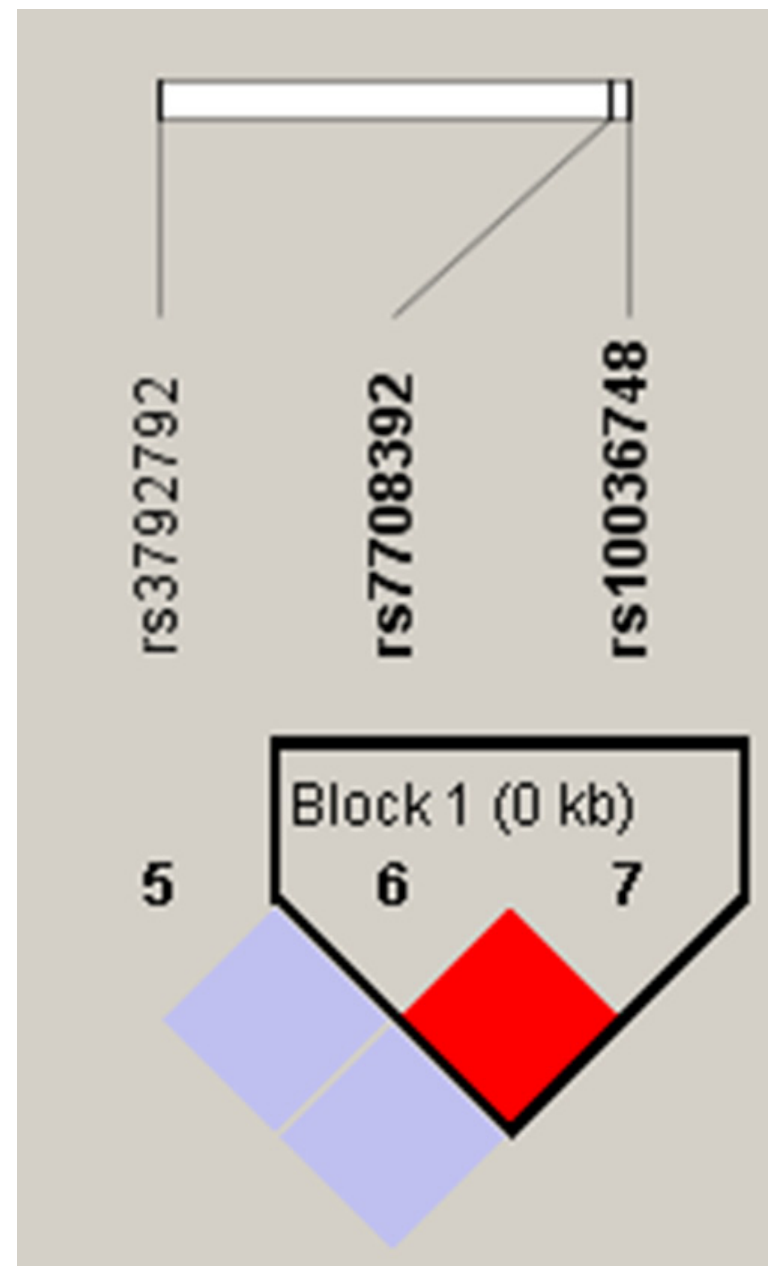

Figure 1: Haplotype block map for part of the SNPs in TNIP1 gene. Standard color frame is used to show LD pattern. Increasing color depth of red indicates increasing degree of LD, with dark red for very strong LD. 
Table 6: Summary of the primers used for the analysis of the TNIP1 polymorphisms

\begin{tabular}{llll}
\hline SNP & First PCRP $\left(\mathbf{5}^{\prime} \rightarrow \mathbf{3}^{\prime}\right)$ & Second PCRP $\left(\mathbf{5}^{\prime} \rightarrow \mathbf{3}^{\prime}\right)$ & UEP SEQ $\left(\mathbf{5}^{\prime} \rightarrow \mathbf{3}^{\prime}\right)$ \\
\hline \multirow{2}{*}{ rs3792792 } & ACGTTGGATGCTC & ACGTTGGATGATGG & ccctTTACGGCCA \\
& AGATCAGTTCACTCCTC & CAGCTGTTACGGCCAC & CCACCAAGCATG \\
\multirow{2}{*}{ rs4958881 } & ACGTTGGATGCAC & ACGTTGGATGTGC & GGATGAAAGGAAGTGAGA \\
& AAATATGTGGACAGTTT & AATTCCACCCAAGGATG & \\
\multirow{2}{*}{ rs7708392 } & ACGTTGGATGAGG & ACGTTGGATGGGG & ggggaTGGAACTTA \\
& CCAACTGGTCAATTCTC & TCTCTTCTGGAACTTAG & GTAGACTAGTCA \\
\multirow{2}{*}{ rs10036748 } & ACGTTGGATGGCAAAGCA & ACGTTGGATGGCCAG & tgtcATGCAAAA \\
& GCCCCTTTTTC & TGGGAATGCAAAATG & TGAAACAGACACTT \\
\hline
\end{tabular}

SNP, single-nucleotide ploymorphisms; PCRP, PCR primer; UEP, Un-extended mini-sequencing primer.

Several limitations in our present case-control study should be pointed out. First, the small sample size cannot provide sufficient statistical power to reflect the real association between SNPs in the TNIP1 gene and GC. Second, the associations between polymorphisms in the TNIP1 gene and histological subtype of GC were not discussed. Third, Helicobacter pylori infection and dietary habits are crucial factors in risk of gastric carcinogenesis, which were not included due to lack of corresponding clinical information. In addition, the associations we reported have not been investigated before; thus, further research with a larger sample size is needed to confirm our data.

Our present study provides evidence that single nucleotide polymorphisms in the TNIP1 gene are associated with GC in the Chinese Han population from Northwest China. It is possible that these variants are GC risk factors and these data can provide a theoretical foundation for other researchers to further study the association between the TNIP1 gene and GC risk in the Chinese Han or other populations.

\section{MATERIALS AND METHODS}

\section{Study subjects}

This study consisted of 302 GC patients and 300 healthy controls (Table 1). The cases were recruited at the Second Affiliated Hospital, Xi'an Jiaotong University and Shaanxi Province People's Hospital between March 2013 and June 2015. Inclusion and exclusion criterias were as follows: (1) All subjects were ethnically homogeneous Chinese Han and residents of Northwest China. (2) All included cases were recently diagnosed and histopathologically confirmed gastric cancer according to the World Health Organization (WHO) criteria [24]. (3) None of the GC patients had inflammatory, autoimmune disorders, and family history of cancer. (4) All patients who underwent radiotherapy and/ or chemotherapy were excluded. All healthy controls had never been diagnosed with cancer and were interviewed by professional interviewers for their gender, age, and exposure to exogenous risk factors for malignant tumor such as smoking status, poor diet, occupational exposure to carcinogens, and family history of cancer. Those who possessed these exogenous risk factors were excluded from our study. All individuals involved in this study gave written informed consent for the genetic analysis. The study protocol was approved by the ethics committee of the Second Affiliated Hospital, Xi'an Jiaotong University.

\section{DNA isolation and genotyping}

Blood samples were drawn from all subjects before they had received other therapies, such as surgery, radiotherapy, and chemotherapy. Genomic DNA was isolated from peripheral blood leukocytes in whole blood using the GoldMag-Mini Purification Kit (GoldMag Co. Ltd. Xi'an city, China) according to the manufacturer's instructions. DNA concentrations were measured using the NanoDrop 2000 (Thermo Scientific, Waltham, Massachusetts, USA) at wavelengths of A260 and A280 $\mathrm{nm}$. DNA was quantified and diluted using QIAgility to a final concentration of $20 \mathrm{ng} / \mu \mathrm{l}$. Using the HapMap database, we searched SNPs from the TNIP1 gene and restricted with a minor allele frequency (MAF) $>5 \%$ in the Chinese Han Beijing population. Four SNPs in the TNIPl gene were randomly selected for further genotyping. Primers for amplification process and single base extension reactions were designed with Sequenom Mass-ARRAY Assay Design 3.0 Software (Sequenom Co. Ltd, San Diego, California, USA) [25]. Subsequent SNP genotyping was performed using Sequenom Mass-ARRAY RS1000 (Sequenom, San Diego, CA). The corresponding primers used for each SNP in the present study are listed in Table 6. Data management and analysis were performed using Sequenom Typer 4.0 Software (Sequenom Co. Ltd) [25, 26].

\section{Statistical analysis}

All statistical analysis was conducted using Microsoft Excel and SPSS 16.0 (SPSS, Chicago IL USA). 
Allele frequency of each SNP in the control subjects was analyzed using the exact test to determine whether the four SNPs departed from Hardy-Weinberg equilibrium (HWE). We used Chi-square test/Fisher's exact test to compare the differences in SNP allele and genotype distribution between GC cases and controls [27]. Then the association between each SNP and GC was assessed under three genetic models: dominant, recessive and additive model using PLINK software, a web-based program available at http://pngu.mgh.harvard.edu/purcell/plink/. Finally, the SHEsis software platform (http://www.nhgg.org/analysis) and Haploview software package (version 4.2) were used to analyze and visualize patterns of linkage disequilibrium (LD) and haplotype construction [28]. The odd ratio (OR) and $95 \%$ confidence intervals (CI), calculated by using unconditional logistic regression analysis with adjustments for age and gender, were used to assess the association between each SNP and the risk of GC [29]. Two-sided $P \leq 0.05$ was considered statistically significant for all statistical tests.

\section{ACKNOWLEDGMENTS}

We thank all the patients and individuals for their participation and all the physicians and nurses of the Second Department of General Surgery, Shaanxi Province People's Hospital for their offers of gastric carcinoma blood samples.

\section{CONFLICTS OF INTEREST}

The authors have declared that they have no competing financial interests exist.

\section{REFERENCES}

1. Ferlay J, Shin HR, Bray F, Forman D, Mathers C, Parkin DM. Estimates of worldwide burden of cancer in 2008: GLOBOCAN 2008. International journal of cancer. 2010; 127:2893-2917.

2. Washington K. 7th edition of the AJCC cancer staging manual: stomach. Annals of surgical oncology. 2010; 17:3077-3079.

3. Pan Y, Bi F, Liu N, Xue Y, Yao X, Zheng Y, Fan D. Expression of seven main Rho family members in gastric carcinoma. Biochemical and biophysical research communications. 2004; 315:686-691.

4. Zhang RG, Duan GC, Fan QT, Chen SY. Role of Helicobacter pylori infection in pathogenesis of gastric carcinoma. World journal of gastrointestinal pathophysiology. 2016; 7:97-107.

5. Zebrowska M, Salagacka A, Jelen A, Jesionek-Kupnicka D, Mirowski M, Balcerczak E. Is the ABCB1 gene associated with the increased risk of gastric cancer development?-preliminary research. Pathology, research and practice. 2014; 210:872-878.

6. Yin $\mathrm{M}, \mathrm{Hu} \mathrm{Z}$, Tan D, Ajani JA, Wei Q. Molecular epidemiology of genetic susceptibility to gastric cancer: focus on single nucleotide polymorphisms in gastric carcinogenesis. American journal of translational research. 2009; 1:44-54.

7. Jang BG, Kim WH. Molecular pathology of gastric carcinoma. Pathobiology. 2011; 78:302-310.

8. Gurevich I, Zhang C, Francis N, Aneskievich BJ. TNIP1, a retinoic acid receptor corepressor and A20-binding inhibitor of NF-kappaB, distributes to both nuclear and cytoplasmic locations. J Histochem Cytochem. 2011; 59:1101-1112.

9. Baek MK, Kim MH, Jang HJ, Park JS, Chung IJ, Shin BA, Ahn BW, Jung YD. EGF stimulates uPAR expression and cell invasiveness through ERK, AP-1, and NF-kappaB signaling in human gastric carcinoma cells. Oncology reports. 2008; 20:1569-1575.

10. Blakely CM, Pazarentzos E, Olivas V, Asthana S, Yan JJ, Tan I, Hrustanovic G, Chan E, Lin L, Neel DS, Newton W, Bobb KL, Fouts TR, Meshulam J, Gubens MA, Jablons $\mathrm{DM}$, et al. NF-kappaB-activating complex engaged in response to EGFR oncogene inhibition drives tumor cell survival and residual disease in lung cancer. Cell reports. 2015; 11:98-110.

11. Huang L, Verstrepen L, Heyninck K, Wullaert A, Revets H, De Baetselier P, Beyaert R. ABINs inhibit EGF receptormediated NF-kappaB activation and growth of EGF receptor-overexpressing tumour cells. Oncogene. 2008; 27:6131-6140.

12. Wu MS, Hsieh RP, Huang SP, Chang YT, Lin MT, Chang MC, Shun CT, Sheu JC, Lin JT. Association of HLA-DQB1*0301 and HLA-DQB1*0602 with different subtypes of gastric cancer in Taiwan. Jpn J Cancer Res. 2002; 93:404-410.

13. Chai HC, Phipps ME, Othman I, Tan LP, Chua KH. HLA variants rs9271366 and rs9275328 are associated with systemic lupus erythematosus susceptibility in Malays and Chinese. Lupus. 2013; 22:198-204.

14. Takeuchi F, Nakano K, Yamada H, Hong GH, Nabeta H, Yoshida A, Matsuta K, Bannai M, Tokunaga K, Ito K. Association of HLA-DR with progressive systemic sclerosis in Japanese. J Rheumatol. 1994; 21:857-863.

15. Chen J, Lu Y, Zhang H, Ding Y, Ren C, Hua Z, Zhou Y, Deng B, Jin G, Hu Z, Xu Y, Shen H. A nonsynonymous polymorphism in IL23R gene is associated with risk of gastric cancer in a Chinese population. Mol Carcinog. 2010; 49:862-868.

16. Safrany E, Hobor R, Jakab L, Tarr T, Csongei V, Jaromi L, Sipeky C, Valasek A, Zeher M, Fust G, Czirjak L, Melegh B. Interleukin-23 receptor gene variants in Hungarian systemic lupus erythematosus patients. Inflamm Res. 2010; 59:159-164. 
17. Cen H, Zhou M, Leng RX, Wang W, Feng CC, Li BZ, Zhu Y, Yang XK, Yang M, Zhai Y, Zhang M, Hu LF, Li R, Chen GM, Chen H, Pan HF, et al. Genetic interaction between genes involved in NF-kappaB signaling pathway in systemic lupus erythematosus. Mol Immunol. 2013; 56:643-648.

18. Kawasaki A, Ito S, Furukawa H, Hayashi T, Goto D, Matsumoto I, Kusaoi M, Ohashi J, Graham RR, Matsuta K, Behrens TW, Tohma S, Takasaki Y, Hashimoto H, Sumida $\mathrm{T}$, Tsuchiya N. Association of TNFAIP3 interacting protein 1, TNIP1 with systemic lupus erythematosus in a Japanese population: a case-control association study. Arthritis Res Ther. 2010; 12:R174.

19. Bossini-Castillo L, Martin JE, Broen J, Simeon CP, Beretta L, Gorlova OY, Vonk MC, Ortego-Centeno N, Espinosa G, Carreira P, Garcia de la Pena P, Oreiro N, Roman-Ivorra JA, Castillo MJ, Gonzalez-Gay MA, Saez-Comet L, et al. Confirmation of TNIP1 but not RHOB and PSORS1C1 as systemic sclerosis risk factors in a large independent replication study. Ann Rheum Dis. 2013; 72:602-607.

20. Ma L, Zeng J, Guo Q, Liang X, Shen L, Li S, Sun Y, Li W, Liu $\mathrm{S}$, Yu H, Chen C, Jia J. Mutual amplification of HNF4alpha and IL-1R1 composes an inflammatory circuit in Helicobacter pylori associated gastric carcinogenesis. Oncotarget. 2016; 7:11349-63. doi: 10.18632/oncotarget.7239.

21. Karin M, Cao Y, Greten FR, Li ZW. NF-kappaB in cancer: from innocent bystander to major culprit. Nature reviews Cancer. 2002; 2:301-310.

22. Verstrepen L, Carpentier I, Verhelst K, Beyaert R. ABINs: A20 binding inhibitors of NF-kappa B and apoptosis signaling. Biochemical pharmacology. 2009; 78:105-114.
23. Gambhir S, Vyas D, Hollis M, Aekka A, Vyas A. Nuclear factor kappa B role in inflammation associated gastrointestinal malignancies. World journal of gastroenterology. 2015; 21:3174-3183.

24. Hamilton S, Vogelstein B, Kudo S, Riboli E, Nakamura S, Hainaut P, Rubio C, Sobin L, Fogt F, Winawer S. Carcinoma of the colon and rectum. Pathology and genetics of tumours of the digestive system IARC Press, Lyon. 2000:110-111.

25. Gabriel S, Ziaugra L, Tabbaa D. SNP genotyping using the Sequenom MassARRAY iPLEX platform. Current protocols in human genetics / editorial board, Jonathan L Haines [et al]. 2009; Chapter 2:Unit 2.12.

26. Thomas RK, Baker AC, Debiasi RM, Winckler W, Laframboise T, Lin WM, Wang M, Feng W, Zander T, MacConaill L, Lee JC, Nicoletti R, Hatton C, Goyette M, Girard L, Majmudar K, et al. High-throughput oncogene mutation profiling in human cancer. Nature genetics. 2007; 39:347-351.

27. Adamec C. [EXAMPLE OF THE USE OF THE NONPARAMETRIC TEST. TEST X2 FOR COMPARISON OF 2 INDEPENDENT EXAMPLES]. Ceskoslovenske zdravotnictvi. 1964; 12:613-619.

28. Shi YY, He L. SHEsis, a powerful software platform for analyses of linkage disequilibrium, haplotype construction, and genetic association at polymorphism loci. Cell research. 2005; 15:97-98.

29. Sole X, Guino E, Valls J, Iniesta R, Moreno V. SNPStats: a web tool for the analysis of association studies. Bioinformatics (Oxford, England). 2006; 22:1928-1929. 